\title{
Endoscopic or Surgical Resection for Patients with 2-5cm Gastric Gastrointestinal Stromal Tumors: A Single-Center 12-Year Experience from China
}

This article was published in the following Dove Press journal: Cancer Management and Research

\author{
Tianxiang Lei $\mathbb{D}^{1, *}$ \\ Fengbo $\operatorname{Tan}^{1}{ }^{1} *$ \\ Heli Liu (D) \\ Miao Ouyang ${ }^{2}$ \\ Haiyan Zhou ${ }^{3}$ \\ Peng Liu' \\ Xianhui Zhao' \\ Bin $\mathrm{Li}^{4}$
}

'Department of Gastrointestinal Surgery, Xiangya Hospital, Central South University, Changsha, Hunan, People's Republic of China; ${ }^{2}$ Department of Gastroenterology, Xiangya Hospital, Central South University, Changsha, Hunan, People's Republic of China;

${ }^{3}$ Department of Pathology, Xiangya Hospital, Central South University, Changsha, Hunan, People's Republic of China; ${ }^{4}$ Department of Oncology, Xiangya Hospital, Central South University, Changsha, Hunan, People's Republic of China

*These authors contributed equally to this work
Correspondence: Heli Liu; Miao Ouyang Email heliliu@csu.edu.cn;

oym3399@csu.edu.cn
Purpose: The surgical or endoscopic resection is the current treatment modality for $2-5 \mathrm{~cm}$ gastric gastrointestinal stromal tumors (GISTs). However, evidence is lacking as to which treatment modality is better. Our objective is to provide a new reference for the standardization of the treatment of $2-5 \mathrm{~cm}$ gastric GISTs.

Patients and Methods: A retrospective study was conducted on 177 patients who underwent resection for 2-5cm gastric GISTs between January 2007 and July 2019 at Xiangya Hospital of Central South University. The cases were divided into surgical group $(n=118)$ and endoscopic group $(n=59)$. The clinical data, pathological and genetic characteristics, shortand long-term outcomes were compared.

Results: Symptoms showed more obvious in the surgical group including abdominal pain and bleeding. In the endoscopic group, tumor size was smaller $(\mathrm{p}<0.001)$, and risk classification was lower $(\mathrm{p}<0.001)$. Patients in the endoscopic group had shorter anal exhaust time $(\mathrm{p}<0.001)$ and lesser hospital cost $(\mathrm{p}<0.001)$. However, the incidence rate of complications $(25.42$ vs $4.20 \% ; \mathrm{p}<0.001)$ and reoperation $(22.03$ vs $0.00 \%$; $<0.001)$ in the endoscopic group was relatively higher than these in the surgical group. There was no significant difference in recurrence-free survival or overall survival between two groups.

Conclusion: Gastric GISTs of $2-5 \mathrm{~cm}$ may be suitable to select laparoscopic surgery.

Keywords: gastric gastrointestinal stromal tumors, surgical resection, endoscopic resection, prognosis

\section{Introduction}

Gastrointestinal stromal tumors (GISTs) are the most common mesenchymal tumors of the gastrointestinal tract. They can arise in any part of the digestive tract, such as in the stomach (50-60\%), in the small intestine (30-35\%), in the colon and rectum $(5 \%)$, or in the esophagus $(<1 \%)$. ${ }^{1}$ The estimated incidence of GISTs worldwide is about 2 per 100,000 people. $^{2}$ Although target drugs like Imatinib have shown efficacy in the treatment of GISTs, ${ }^{3}$ surgical resection remains the main treatment modality for primary GISTs. ${ }^{4-6}$ Gastric GISTs $<2 \mathrm{~cm}$ with no signs of malignancy may be managed with active surveillance. However, endoscopic resection is recommended for patients with a high-risk of recurrence (irregular echoic lesion in ultrasound gastroscopy). ${ }^{7}$ For gastric GISTs with tumor diameter $>5 \mathrm{~cm}$, due to their intermediate or high risk of recurrence, surgical resection (open or laparoscopic surgery) is the preferred treatment option. For 2-5 cm gastric GISTs, there is currently not a high level of evidence-based medicine supporting a clear best choice of treatment for managing these tumors. 
Accordingly, this study is a retrospective analysis of the data of 177 gastric GISTs patients who underwent endoscopic or surgical resection at Xiangya Hospital of Central South University (Changsha, China) from January 2007 to July 2019. Our objective is to provide a new reference for the standardization of the treatment of $2-5 \mathrm{~cm}$ gastric GISTs.

\section{Patients and Methods}

\section{Patients}

From January 2007 to July 2019, a total of 879 patients with GISTs underwent surgical or endoscopic treatment at Xiangya Hospital of Central South University. In order to retrospectively analyze the data on clinical features, diagnosis, treatment, and prognosis, we established inclusion and exclusion criteria (Figure 1). The inclusion criteria were the following: (1) tumor size of $2-5 \mathrm{~cm}$; (2) tumor was located in the stomach. The exclusion criteria were as follows: (1) the clinical data was incomplete $(\mathrm{n}=45)$; (2) there were multiple GISTs ( $\mathrm{n}=2)$; (3) patients had other cancers, such as gastric cancer, liver cancer, esophageal cancer or pancreatic cancer $(\mathrm{n}=9)$; (4) patients have recurrent GISTs (n=7); (5) patients underwent simultaneous resection of other organs, such as the hepatectomy $(\mathrm{n}=4)$; (6) patients received preoperative treatments, such as Imatinib $(n=3)$. Ultimately, 177 cases were included in the study, among which 59 patients underwent endoscopic resection of the tumor (endoscopic group), and 118 underwent surgical resection of the tumor (surgical group). This study protocol was approved by the Medical Ethics Committee of Xiangya Hospital of Central South University, and written informed consent was obtained from all patients before surgical or endoscopic resection.

\section{Pathological Diagnosis}

Within 30 minutes after resection, GISTs were fixed in a $10 \%$ buffered formalin solution with a standard surgical pathology specimen processing protocol for subsequent pathological evaluation. Histopathology analysis revealed cell features. Also, the number of mitosis per 50 highpower field was counted by hematoxylin and eosin staining. GISTs markers CD34, CD117 and DOG1 were detected by immunohistochemical analysis. After complete removal of the tumor, primary GISTs were examined and classified into four grades, namely very low risk, low risk, intermediate risk and high risk based on a modified National Institutes of Health (NIH) classification system (2008). Finally, the pathologist (Haiyan Zhou) determined and recorded the location of the GISTs, their maximum

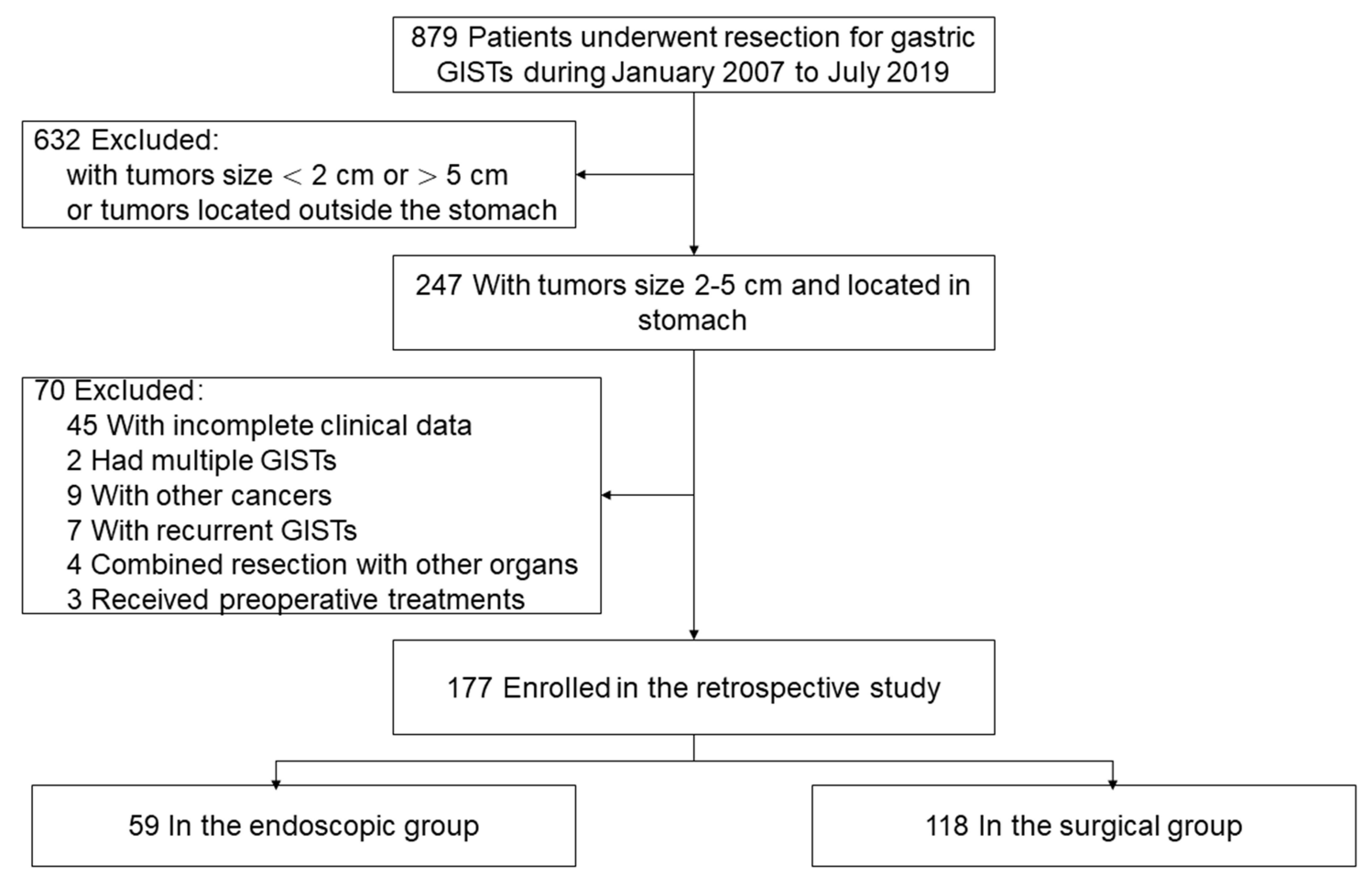

Figure I Flowchart of patients selection process. 
diameter and other related data. Gene mutation analysis (C-KIT 9, 11, 13, 17 and PDGFRA 12, 18) was performed for the tumor of some patients after the surgery.

\section{Interventions}

\section{Preoperative Examination}

Before surgery, patients were examined using computed tomography (CT) to exclude adjacent organ infiltration and metastases. In addition, they underwent either gastroscopy or ultrasound gastroscopy to determine the location and size of the gastric GISTs. Cardiopulmonary examinations, including electrocardiography and pulmonary function test, were performed on the patients to assess their tolerance to surgery.

\section{Surgical Resection}

In the surgical group, all 118 patients received general anesthesia with trachea cannula for either laparoscopy or open surgery. The choice of surgical modality was mainly based on the preoperative evaluation and the patients' physical condition. In the open surgery cases, first a straight $15-$ $\mathrm{cm}$ incision was made in the middle of the upper abdomen, then surgeons fully exposed the location of the tumor, dissected the blood vessels and the omentum around the tumor, and surgeons eventually chose a suitable surgical procedure (Billroth I, Billroth II or partial gastrectomy) according to the location of the tumor. All tumors were completely resected to achieve $\mathrm{R} 0$ resection and the incision margin was $2 \mathrm{~cm}$ beyond the tumor margin. In the laparoscopic cases (Figure 2), first a needle was used to establish the pneumoperitoneum using a maintenance pressure of about 12-15 mmHg. Subsequently, the surgeons inserted 5 trocars into the abdomen and confirmed the location of the tumor in a laparoscopic field of vision. Then, they dissected the omentum and the blood vessels to expose the tumor and resected it. Finally, a 5-cm midline abdominal incision was carefully made and the tumor was removed. All surgeries were performed by surgeons with similar high levels of experience. After the surgery, a gastric tube and a urinary catheter were routinely retained, and a drainage tube was placed at the tumor resection bed according to intraoperative conditions. During the postoperative period, all patients fasted and received prophylactic antibiotic treatment, nutritional support and other comprehensive treatment according to the physiological requirements and biochemical indices of each patient.

\section{Endoscopic Resection}

For the endoscopic group, all 59 patients received intravenous anesthesia. Currently, there are mainly 5 types of endoscopic procedures for treating gastric GISTs, ${ }^{8}$ namely endoscopic submucosal dissection, endoscopic fullthickness resection (Figure 3), endoscopic submucosal excavation, endoscopic band ligation, and submucosal tunnel endoscopic resection. In our study, all the surgeries were performed by one expert endoscopist (Miao Ouyang). If massive bleeding or incomplete resection occurred during endoscopic resection, surgical interventions were performed for patient safety. After the surgery, patients were treated with conventional methods, including nutritional support, fasting and gastrointestinal decompression.

\section{Data Collection}

In the hospital information system of Xiangya Hospital of Central South University, we recorded the clinical data of all patients, including their name, age, sex, major complaint, hospitalization date, hospital stay, hospitalization cost, etc. We also recorded surgical and endoscopic resection-related data in operative and medical records, including the surgical procedure, complications, gastric intubation duration, anal exhaust time, postoperative

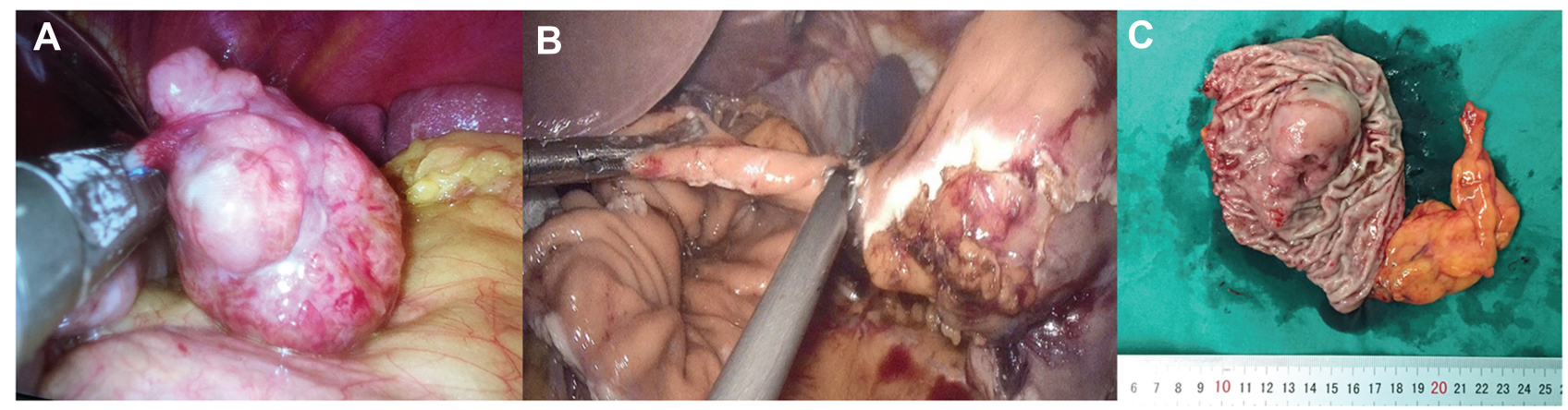

Figure 2 Laparoscopic resection of gastric GIST. (A) Direct resection by liner stapler. (B) Open the stomach cavity and cut with ultrasonic scalpel along the edge of the tumor, when the bottom of the tumor cannot be identified from outside of the stomach. (C) Postoperative specimen and the results of the final postoperative examination show this tumor is GIST with the size $<5 \mathrm{~cm}$. 

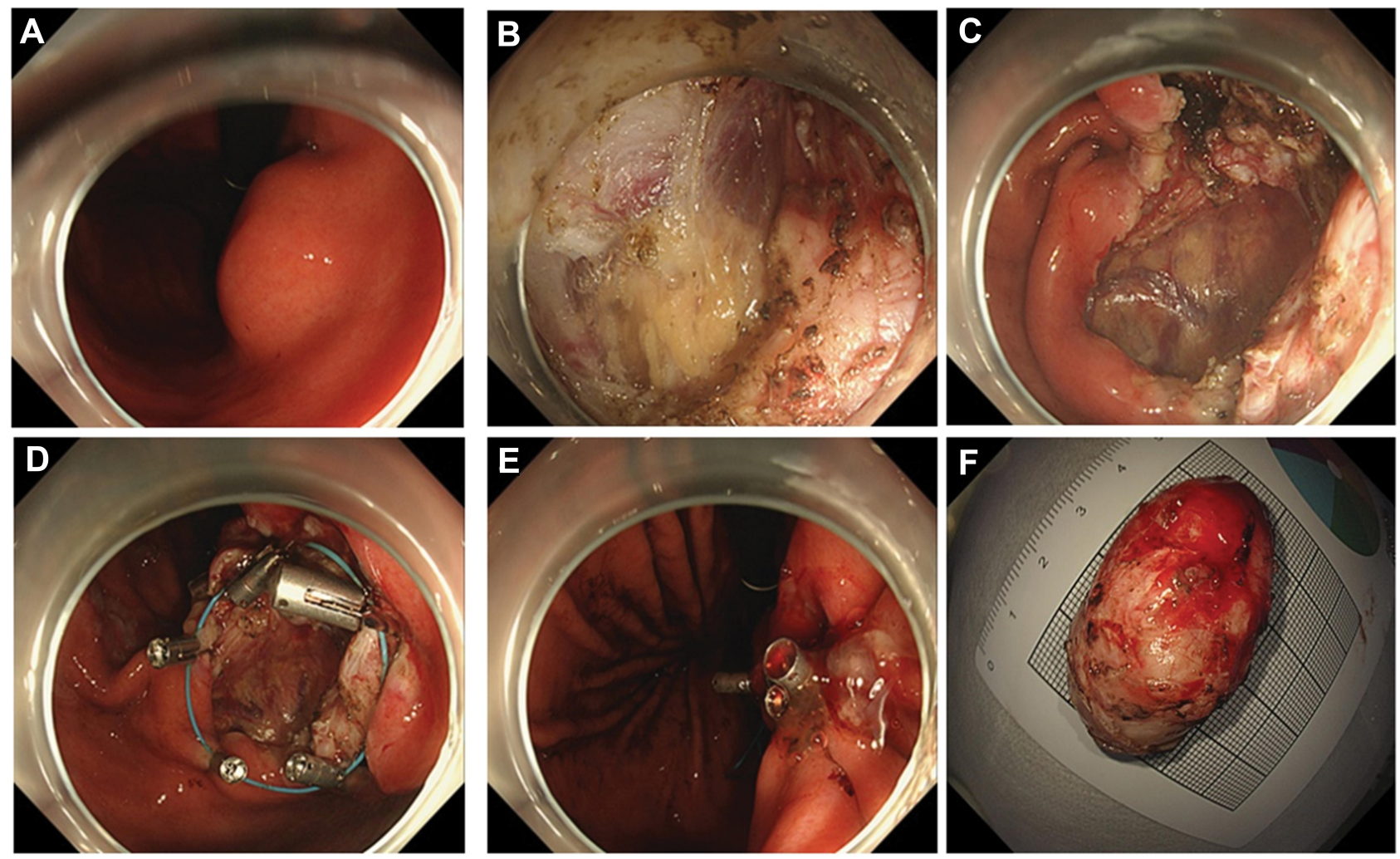

Figure 3 A 65 years old woman, complained upper abdominal distention for 3 months. (A) A submucous lesion (about $3.5 \times 2.0 \mathrm{~cm}$ in size) was found in the body of stomach by gastroscopy. (B) She received an EFTR (endoscopic full-thickness resection) procedure under an experienced endoscopist. (C) The wound in stomach was large and deep after the lesion was removed. (D and $\mathbf{E})$ The wound was closed by detachable snare loop technique. (F) The specimen of the removed lesion, with the size about $3.0 \times 4.5 \mathrm{~cm}$, and the GIST diagnosis was confirmed by the pathologist.

hospital stay, hospital cost, and reoperation. Tumor location and growth type were recorded by preoperative examinations, like CT scan, gastroscopy, as well as by postoperative pathological analysis results. The pathological characteristics, including tumor size, mitotic index, modified NIH risk classification, CD117, CD34, DOG1, and gene mutations were recorded. Patients who had suffered recurrence were recorded in outpatient department follow-up from July 2019 to January 2020. Additionally, whether the patient had experienced recurrence or died was also recorded by telephone follow-up in February 2020.

\section{Complications}

In our study, complications were determined using the Clavien-Dindo classification. ${ }^{9}$ Grade I: Any deviation from the normal postoperative course without the need for pharmacological treatment or surgical, endoscopic and radiological interventions. Acceptable therapeutic regimens are: drugs as antiemetics, antipyretics, analgetics, diuretics and electrolytes, and physiotherapy. Grade
II: Requiring pharmacological treatment with drugs other than such allowed for grade I complications. Grade III: Requiring surgical, endoscopic or radiological intervention; Grade III-a: intervention not under general anesthesia; Grade III-b: intervention under general anesthesia. Grade IV: Life-threatening complication. Grade V: Death of a patient.

\section{Postoperative Follow-Up}

Follow-up was regularly conducted by telephone or outpatient service. Any possible side effects, recurrence time and pattern, death time and cause of the included cases were recorded. The follow-up time was calculated starting from the time of patient's operation, and the cut-off time was the date of death or the follow-up deadline of February 2020. All patients were routinely reexamined in the outpatient clinic, undergoing routine blood, liver and kidney function tests to evaluate the postoperative recovery, wound healing and postoperative complications at 2 weeks after discharge, and then underwent abdominal CT scan or conventional upper endoscopy during the 
following 3 years to rule out recurrence or metastasis. According to the health insurance policy in Hunan province, China, many patients with intermediate and highrisk GISTs must come to Xiangya hospital's outpatient department to get an Imatinib prescription from a doctor and were routinely treated with Imatinib and placed under surveillance for tumor recurrence.

\section{Statistical Analysis}

Continuous data are expressed as the mean \pm standard deviation or median and range. Categorical data are expressed as the number of cases. Statistical differences between groups were assessed by the $\chi^{2}$ or Fisher's exact test for categorical data and by Student's $t$-test, or the Mann-Whitney $U$-test for continuous data. The overall survival (OS) and recurrence-free survival (RFS) were calculated by the Kaplan-Meier method and compared using a Log rank test. Data were analyzed using the SPSS 25.0 software (IBM Corp., Armonk, NY, USA) for Windows, and values of $\mathrm{P}<0.05$ were considered statistically significant.

\section{Results}

\section{Demographic and Clinical Characteristics}

The demographic and clinical characteristics of the patients are summarized in Table 1 . The median age of patients in the surgical group was 56 years (21-85 years) and 54 years (28-79 years) in the endoscopic group. There were 64 males $(54.24 \%)$ and 54 females $(45.76 \%)$ in the surgical group, and 28 males $(47.46 \%)$ and 31 females $(52.54 \%)$ in the endoscopic group. The localization of the primary tumor in patients of the surgical group was $50(42.37 \%)$ in gastric fundus, $50(42.37 \%)$ in gastric body, $11(9.33 \%)$ in gastric antrum and $7(5.93 \%)$ in gastric cardia, while in patients of the endoscopic group it was $30(50.85 \%)$ in gastric fundus, $19(32.20 \%)$ in gastric body, $4(6.78 \%)$ in gastric antrum and $6(10.17 \%)$ in gastric cardia. There were no significant differences in these features between these groups. However, a significant difference was observed in the growth type between the two groups $(\mathrm{p}<0.001)$. The main symptoms of the patients were abdominal pain, abdominal distension, bleeding, and no symptoms. We classified symptoms like melena and hematemesis as bleeding. All patients without any symptoms were inadvertently identified as gastric tumors during physical examinations. In the surgical group, the most common clinical symptom was abdominal pain $(45.76 \%)$, while in the endoscopic group, it was no symptoms $(40.68 \%)$.

\section{Pathological and Genetic Characteristics}

As shown in Table 2, there were significant differences in tumor size and risk classification between the two groups $(\mathrm{p}<0.001)$. The average tumor size was $3.78 \pm 1.10 \mathrm{~cm}$ $(2.0-5.0 \mathrm{~cm})$ and $2.74 \pm 0.92 \mathrm{~cm}(2.0-5.0 \mathrm{~cm})$ in the surgical and endoscopic groups, respectively. Among the

Table I Demographic and Clinical Characteristics of Two Groups

\begin{tabular}{|c|c|c|c|c|}
\hline & & Surgical Resection $(n=|| 8)$ & Endoscopic Resection $(n=59)$ & $P$ value \\
\hline Age (years) & $\begin{array}{l}\text { Median (Range) } \\
\text { Mean } \pm \text { SD }\end{array}$ & $\begin{array}{l}56(21-85) \\
55 \pm 12\end{array}$ & $\begin{array}{l}54(28-79) \\
55 \pm 11\end{array}$ & 0.950 \\
\hline Gender (n, \%) & $\begin{array}{l}\text { Male } \\
\text { Female }\end{array}$ & $\begin{array}{l}64 \text { (54.24\%) } \\
54 \text { (45.76\%) }\end{array}$ & $\begin{array}{l}28(47.46 \%) \\
31 \text { (52.54\%) }\end{array}$ & 0.395 \\
\hline Symptoms (n, \%) & $\begin{array}{l}\text { Abdominal pain } \\
\text { Abdominal distention } \\
\text { Bleeding } \\
\text { No symptoms }\end{array}$ & $\begin{array}{l}54(45.76 \%) \\
9(7.63 \%) \\
30(25.42 \%) \\
25(21.19 \%)\end{array}$ & $\begin{array}{l}19(32.20 \%) \\
12(20.34 \%) \\
4(6.78 \%) \\
24(40.68 \%)\end{array}$ & $\begin{array}{l}0.084 \\
0.014 \\
0.003 \\
0.006\end{array}$ \\
\hline Tumor location (n, \%) & $\begin{array}{l}\text { Gastric cardia } \\
\text { Gastric fundus } \\
\text { Gastric body } \\
\text { Gastric antrum }\end{array}$ & $\begin{array}{l}7(5.93 \%) \\
50(42.37 \%) \\
50(42.37 \%) \\
I I(9.33 \%)\end{array}$ & $\begin{array}{l}6(10.17 \%) \\
30(50.85 \%) \\
19(32.20 \%), \\
4(6.78 \%)\end{array}$ & 0.403 \\
\hline Growth type (n, \%) & $\begin{array}{l}\text { Intraluminal } \\
\text { Extraluminal }\end{array}$ & $\begin{array}{l}63(53.39 \%) \\
55(46.61 \%)\end{array}$ & $\begin{array}{l}57(96.61 \%) \\
2(3.39 \%)\end{array}$ & 0.000 \\
\hline
\end{tabular}

Abbreviation: SD, standard deviation. 
Table 2 Pathological Characteristics of Two Groups

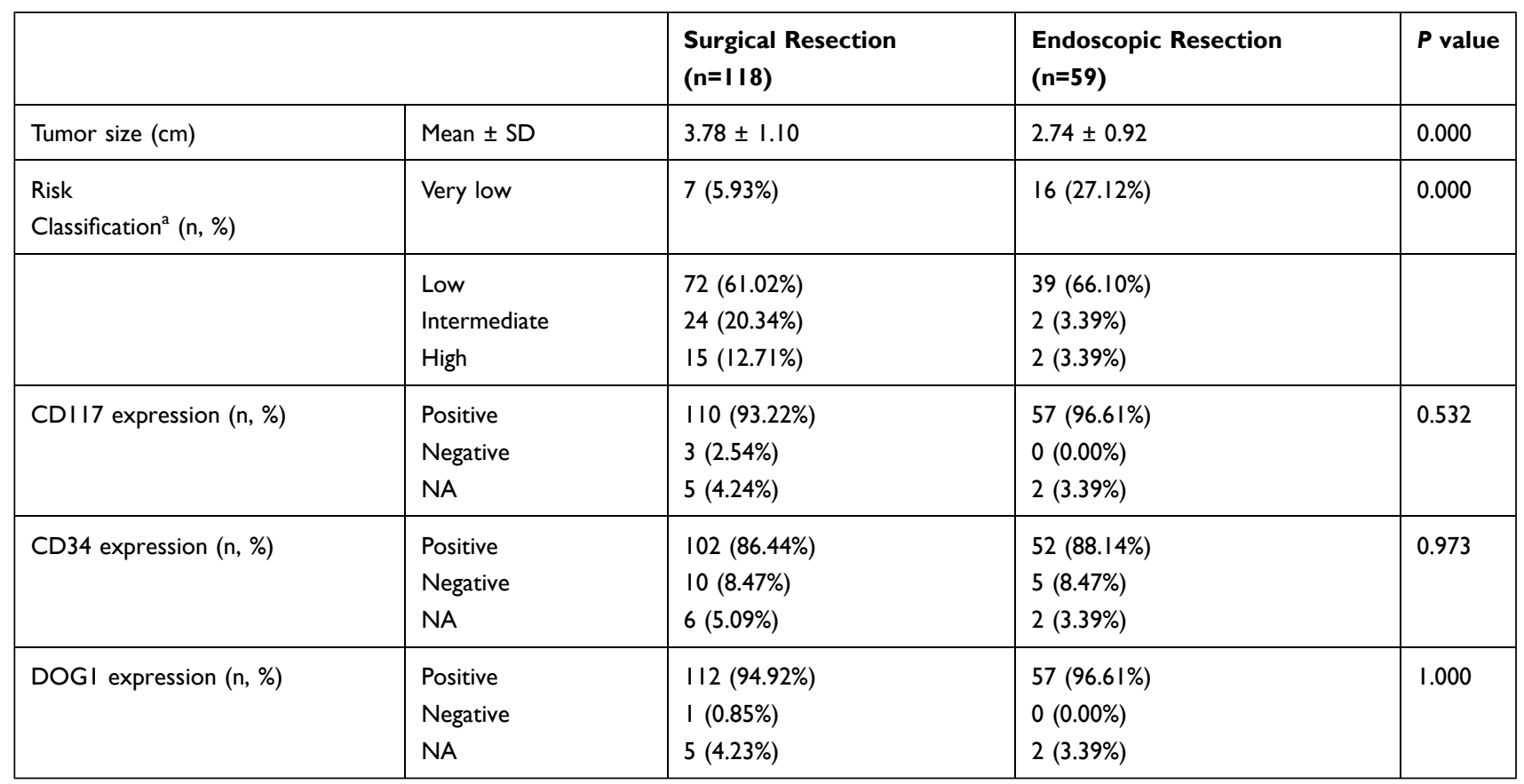

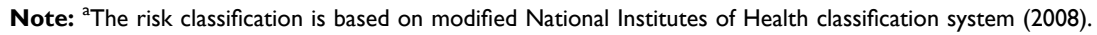

Abbreviations: DOGI, discovered on GIST-I; SD, standard deviation; NA, data unavailable.

postoperative pathological results of the 177 patients, tumor necrosis was found in one patient in the surgical group and calcification in one patient in the endoscopic group. According to the modified NIH classification system (2008), ${ }^{5}$ primary GISTs should be staged, then the risk of tumor recurrence was evaluated. In the surgical group, the majority of the patients were in the low risk (61.02\%) and intermediate risk $(20.34 \%)$ subgroups, while in the endoscopic group the majority of the patients were in the very low risk (27.12\%) and low risk (66.10\%) subgroups.

As shown in Table 3, the immunohistochemical and genetic characteristics show no significant difference between two groups. The tumors from 167 (92.78\%) and $3(1.67 \%)$ patients were positive and negative, respectively, for the expression of CD117. The tumors from $154(86.03 \%)$ and $15(8.38 \%)$ patients, were positive and negative, respectively, for the expression of CD34. The tumors from $169(93.89 \%)$ and $1(0.56 \%)$ patients were positive and negative, respectively, for the expression of DOG1. The gene mutation analysis is helpful for the diagnosis of some ambiguous cases, to predict the effectiveness of targeted drugs and provide guidance for clinical treatment. ${ }^{10}$ The analysis of gene mutations included exons 9, 11, 13 and 17 of C-KIT and exons 12 and 18 of PDGFRA. Mutation analysis of these genes was performed in 31 patients. Gene mutation analysis was performed in 24 patients in the surgical group. A total of 19 patients (79.17\%) had mutations in exon 11 of $C-K I T$, one patient (4.17\%) had a mutation in exon 13 of C-KIT, 4 patients (16.67\%) had a mutation in exon 18 of PDGFRA, and no patient had any mutation in exon 9, 17 of C-KIT and exon 12 of PDGFRA. In the surgical group, it should be noted that one patient had two mutations, which were at exon11 and 13 of C-KIT, and another patient (4.17\%) had a wildtype GIST. The wild-type GIST refers to the case that is consistent with GISTs in pathological diagnosis, but there is no C-KIT or PDGFRA mutation in the molecular detection. ${ }^{11}$ Gene mutation analysis was performed in 7 patients in the endoscopic group. One patient (14.29\%) had a mutation in exon 9 of $C$-KIT, and 6 patients (85.71\%) had a mutation in exon 11 of $C-K I T$.

\section{Short-Term Outcomes}

Short-term outcomes are summarized in Table 4. No significant differences were observed in the gastric intubation duration and postoperative hospital stay. Compared with the surgical group, the anal exhaust time was shorter (2.47 \pm 0.935 vs $3.11 \pm 0.714$ days, $p<0.001)$, and hospital cost was lower $(33,820.34 \pm 11,372.674$ vs $42,977.58 \pm 17,850.799$ $\mathrm{RMB}, \mathrm{p}<0.001)$ in the endoscopic group. 
Table 3 Genetic Characteristics of Two Groups

\begin{tabular}{|c|c|c|c|c|}
\hline & & Surgical Resection $(n=24)$ & Endoscopic Resection $(n=7)$ & $P$ value \\
\hline C-KIT exon $9(\mathrm{n}, \%)$ & $\begin{array}{l}\text { Mutation } \\
\text { Non-mutation }\end{array}$ & $\begin{array}{l}0(0.00 \%) \\
24(100 \%)\end{array}$ & $\begin{array}{l}\text { I (14.29\%) } \\
6 \text { (85.7I\%) }\end{array}$ & 0.226 \\
\hline C-KIT exon II (n, \%) & $\begin{array}{l}\text { Mutation } \\
\text { Non-mutation }\end{array}$ & $\begin{array}{l}19^{\mathrm{a}}(79.17 \%) \\
5(20.83 \%)\end{array}$ & $\begin{array}{l}6(85.7 \mid \%) \\
\text { I (14.29\%) }\end{array}$ & 1.000 \\
\hline C-KIT exon I3 (n, \%) & $\begin{array}{l}\text { Mutation } \\
\text { Non-mutation }\end{array}$ & $\begin{array}{l}I^{\mathrm{a}}(4.17 \%) \\
23(95.83 \%)\end{array}$ & $\begin{array}{l}0(0.00 \%) \\
7(100.00 \%)\end{array}$ & 1.000 \\
\hline C-KIT exon $I 7$ (n, \%) & $\begin{array}{l}\text { Mutation } \\
\text { Non-mutation }\end{array}$ & $\begin{array}{l}0(0.00 \%) \\
24(100.00 \%)\end{array}$ & $\begin{array}{l}0(0.00 \%) \\
7(100.00 \%)\end{array}$ & - \\
\hline PDGFRA exon 12 (n, \%) & $\begin{array}{l}\text { Mutation } \\
\text { Non-mutation }\end{array}$ & $\begin{array}{l}0(0.00 \%) \\
24(100.00 \%)\end{array}$ & $\begin{array}{l}0(0.00 \%) \\
7(100.00 \%)\end{array}$ & - \\
\hline PDGFRA exon 18 (n, \%) & $\begin{array}{l}\text { Mutation } \\
\text { Non-mutation }\end{array}$ & $\begin{array}{l}4(16.67 \%) \\
20(83.33 \%)\end{array}$ & $\begin{array}{l}0(0.00 \%) \\
7(100.00 \%)\end{array}$ & 0.550 \\
\hline Wild - type (n, \%) & $\begin{array}{l}\text { Yes } \\
\text { No }\end{array}$ & $\begin{array}{l}\text { I ( } 4.17 \%) \\
23(95.83 \%)\end{array}$ & $\begin{array}{l}0(0.00 \%) \\
7(100.00 \%)\end{array}$ & 1.000 \\
\hline
\end{tabular}

Note: ane patient has two mutation in exon I I, 13 of kit gene.

In our study, complications among all the 177 patients included post-operative bleeding, intraoperative bleeding, pulmonary embolism, pulmonary infection, leakage and incomplete excision. The incidence of complications in the surgical group was $4.2 \%$ compared with $25.42 \%$ in the endoscopic group $(p<0.001)$. Complications in the surgical group occurred in 5 patients ( 2 cases of pulmonary embolism, 2 cases of pulmonary infection, one case of postoperative bleeding). In the endoscopic group, there were 15 patients with complications (4 cases of intraoperative bleeding, 5 cases of leakage, 6 cases of incomplete excision). Among these patients, 4 patients who experienced intraoperative bleeding during the endoscopic resection were converted to the surgical intervention. Two patients who suffered leakage were treated with fasting, nutritional support and antibiotics. Unfortunately, 3 patients who suffered severe leakage underwent surgical interventions due to the failure of the conservative treatments, and 6 patients without $\mathrm{R} 0$ resection were converted to surgery. According to the Clavien-Dindo classification, 5 patients were classified as grade II in the surgical group. In contrast, in the endoscopic group, there were 15 patients with complications, including 2 cases of Clavien-Dindo grade II, 12 cases of Clavien-Dindo grade III-b and one case of Clavien-Dindo grade IV. All complications were satisfactorily and safely solved. Beside these, we compared more data in the complicated cases $(n=20)$ as shown in Table 5. Analysis results demonstrated that the complicated cases' hospital cost in surgical group is higher than in endoscopic group $(61,478.20 \pm 11,778.432 \mathrm{RMB}$ vs $44,704.07 \pm 11,001.612 \mathrm{RMB} ; \mathrm{p}=0.009)$ and the other differences were not statistically significant.

Furthermore, we evaluated and compared open surgery $(n=96)$ with laparoscopic surgery $(n=22)$ in the surgical group. The statistical outcomes show that the laparoscopic surgery group had a shorter hospital stay compared with that of the open surgery group $(6.09 \pm 0.465$ days vs $7.79 \pm 0.273$ days; $p=0.002$ ), and hospital cost was higher in the laparoscopic surgery group than that in the open surgery group $(48,367.50 \pm 18,357.626$ RMB vs $41,742.39 \pm 14,608.127$ $\mathrm{RMB} ; \mathrm{p}=0.041)$. However, there was no statistical difference between the two groups regarding gastric intubation duration, anal exhaust time and the incidence of complications.

As shown in Table 6, the reoperation rate in the surgical group was significantly lower than that in the endoscopic group $(0.00 \%$ vs $22.03 \% ; \mathrm{p}<0.001)$. Thus it indicated that the surgical resection is relatively safer. Among the 13 patients with reoperation in the endoscopic group, 4 cases were due to massive intraoperative bleeding, 6 cases were due to incomplete excision, and 3 cases were due to leakage. If patients undergo surgical treatment again, they face an increased risk of surgery. Eventually, most of the patients treated with endoscopy cannot undergo an adequate preoperative preparation.

In order to better provide clinical guidance, we further compared and evaluated the incidence of complications 
Table 4 Short-Term Outcomes of Two Groups

\begin{tabular}{|l|l|l|l|l|}
\hline \multicolumn{2}{|l|}{} & Surgical Resection (n= I I ) & Endoscopic Resection (n=59) & P value \\
\hline Gastric intubation duration (days) & Mean \pm SD & $3.4 \pm 1.798$ & $3.86 \pm 2.439$ & 0.220 \\
\hline Anal exhaust time (days) & Mean \pm SD & $3.11 \pm 0.714$ & $2.47 \pm 0.935$ & 0.000 \\
\hline Postoperative hospital stay (days) & Mean \pm SD & $7.45 \pm 2.663$ & $7.47 \pm 3.607$ & 0.267 \\
\hline Hospital cost (RMB) & Mean \pm SD & $42,977.58 \pm 17,850.799$ & $33,820.34 \pm 11,372.674$ & 0.000 \\
\hline Complications (n, \%) & Total cases & $5(4.24 \%)$ & $15(25.42 \%)$ & 0.000 \\
\hline & Postoperative bleeding & $1(0.84 \%)$ & $0(0.00 \%)$ & 1.000 \\
\hline & Intraoperative bleeding & $0(0.00 \%)$ & $4(6.78 \%)$ & 0.012 \\
\hline & Leakage & $0(0.00 \%)$ & $5(8.47 \%)$ & 0.004 \\
\hline & Pulmonary infection & $2(1.70 \%)$ & $0(0.00 \%)$ & 0.553 \\
\hline & Pulmonary embolism & $2(1.70 \%)$ & $6(10.17 \%)$ & 0.553 \\
\hline & Incomplete excision & $0(0.00 \%)$ & 0.001 \\
\hline
\end{tabular}

Abbreviation: SD, standard deviation.

Table 5 Data of the Complicated Cases in Two Groups

\begin{tabular}{|c|c|c|c|c|}
\hline & & Surgical Resection $(n=5)$ & Endoscopic Resection $(n=15)$ & $P$ value \\
\hline Tumor size $(\mathrm{cm})$ & Mean \pm SD & $4.10 \pm 1.02$ & $3.17 \pm 1.03$ & 0.096 \\
\hline Growth type (n, \%) & $\begin{array}{l}\text { Intraluminal } \\
\text { Extraluminal }\end{array}$ & $\begin{array}{l}4(80.00 \%) \\
\text { I (20.00\%) }\end{array}$ & $\begin{array}{l}13(86.67 \%) \\
2(13.33 \%)\end{array}$ & 0.601 \\
\hline Tumor location (n, \%) & $\begin{array}{l}\text { Gastric cardia } \\
\text { Gastric fundus } \\
\text { Gastric body } \\
\text { Gastric antrum }\end{array}$ & $\begin{array}{l}\text { I (20.00\%) } \\
2(40.00 \%) \\
2(40.00 \%) \\
0(0.00 \%)\end{array}$ & $\begin{array}{l}0(0.00 \%) \\
10(66.67 \%) \\
4(26.67 \%) \\
\text { I (6.66\%) }\end{array}$ & 0.340 \\
\hline Intervention modality (n, \%) & $\begin{array}{l}\text { Conservative treatment } \\
\text { Surgical treatment }\end{array}$ & $\begin{array}{l}5(100.00 \%) \\
0(0.00 \%)\end{array}$ & $\begin{array}{l}2(13.33 \%) \\
13(86.67 \%)\end{array}$ & 1.000 \\
\hline Risk classification $^{\mathrm{a}}(\mathrm{n}, \%)$ & $\begin{array}{l}\text { Very low } \\
\text { Low } \\
\text { Intermediate } \\
\text { High }\end{array}$ & $\begin{array}{l}0(0.00 \%) \\
3(60.00 \%) \\
\text { I }(20.00 \%) \\
\text { I }(20.00 \%)\end{array}$ & $\begin{array}{l}0(0.00 \%) \\
13(86.67 \%) \\
0(0.00 \%) \\
2(13.33 \%)\end{array}$ & 0.249 \\
\hline Hospital cost (RMB) & Mean \pm SD & $61,478.20 \pm 11,778.432$ & $44,704.07 \pm 11,001.612$ & 0.009 \\
\hline
\end{tabular}

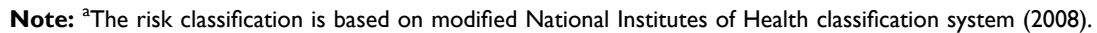

Abbreviation: SD, standard deviation.

Table 6 Causes of Reoperation of Two Groups

\begin{tabular}{|l|l|l|l|l|}
\hline \multicolumn{2}{|l|}{} & Surgical Resection (n=I I8) & Endoscopic Resection (n=59) & $P$ value \\
\hline Reoperation $(\mathrm{n}, \%)$ & Total cases & $0(0 \%)$ & $13(22.03 \%)$ & 0.000 \\
\hline & Intraoperative bleeding & $0(0 \%)$ & $4(6.78 \%)$ & 0.012 \\
\hline & Incomplete excision & $0(0 \%)$ & $6(10.17 \%)$ & 0.001 \\
\hline & Leakage & $0(0 \%)$ & $3(5.08 \%)$ & 0.036 \\
\hline
\end{tabular}


Table 7 The Complications and Reoperation of $2-3 \mathrm{~cm}$ Gastric GISTs in Two Groups

\begin{tabular}{|c|c|c|c|c|}
\hline & & $\begin{array}{l}\text { Surgical Resection } \\
(n=4 I)\end{array}$ & $\begin{array}{l}\text { Endoscopic Resection } \\
(n=44)\end{array}$ & $P$ value \\
\hline Complications (n, \%) & $\begin{array}{l}\text { Total cases } \\
\text { Intraoperative bleeding } \\
\text { Leakage } \\
\text { Pulmonary infection } \\
\text { Pulmonary embolism } \\
\text { Incomplete excision }\end{array}$ & $\begin{array}{l}2(4.88 \%) \\
0(0.00 \%) \\
0(0.00 \%) \\
\text { I }(2.44 \%) \\
\text { I }(2.44 \%) \\
0(0.00 \%)\end{array}$ & $\begin{array}{l}8(18.19 \%) \\
2(4.55 \%) \\
4(9.09 \%) \\
0(0.00 \%) \\
0(0.00 \%) \\
2(4.55 \%)\end{array}$ & $\begin{array}{l}0.091 \\
0.495 \\
0.117 \\
0.482 \\
0.482 \\
0.495\end{array}$ \\
\hline Reoperation (n, \%) & $\begin{array}{l}\text { Total cases } \\
\text { Intraoperative bleeding } \\
\text { Incomplete excision } \\
\text { Leakage }\end{array}$ & $\begin{array}{l}0(0.00 \%) \\
0(0.00 \%) \\
0(0.00 \%) \\
0(0.00 \%)\end{array}$ & $\begin{array}{l}6(13.65 \%) \\
2(4.55 \%) \\
2(4.55 \%) \\
2(4.55 \%)\end{array}$ & $\begin{array}{l}0.026 \\
0.495 \\
0.495 \\
0.495\end{array}$ \\
\hline
\end{tabular}

and reoperation of $2-3 \mathrm{~cm}$ gastric GISTs in two groups (Table 7). In this study, there are 85 patients with $2-3 \mathrm{~cm}$ gastric GISTs, with 41 in the surgical group and 44 in the endoscopic group. For $2-3 \mathrm{~cm}$ gastric, GISTs the incident of reoperation in endoscopic group are still higher than in the surgical group $(13.65 \%$ vs $0.00 \% ; p=0.026)$. Other differences did not reach statistical significance.

\section{Long-Term Outcomes}

Among these 177 patients, 129 were followed up and 48 were lost to follow-up (34 patients in the surgical group, 14 patients in the endoscopic group). In the surgical group, the average follow-up period was $50.69 \pm 31.04$ months (range from 5 to 116 months), while in the endoscopic group the average follow-up period was $40.00 \pm 23.09$ months (range from 8 to 109 months). There was no significant difference in follow-up time between the two groups. In the surgical group, 2 patients with intermediate risk of recurrence died of GIST recurrence at 5 and 19 months, respectively, and one patient died at 49 months due to lung cancer after discharge. In the endoscopic group, nobody died, although the tumor recurred in one patient at 37 months after the endoscopic surgery (recurred in January 2020) and was waiting for the surgical operation.

The 3-year OS and 5-year OS rate were 98.2 (2/118) and $96.8 \%$ (3/118) for the surgical group, and $100.0(0 / 59)$ and $100.0 \%(0 / 59)$ for the endoscopic group, respectively. The 3 -year RFS rate was $98.2(2 / 118)$ and $97.6 \%(1 / 59)$ in the surgical and endoscopic groups, respectively. According to the results of the Kaplan-Meier analysis, there was no significant difference between the surgical and endoscopic groups in OS $(p=0.251)$ and RFS $(p=0.978)$ (Figure 4).
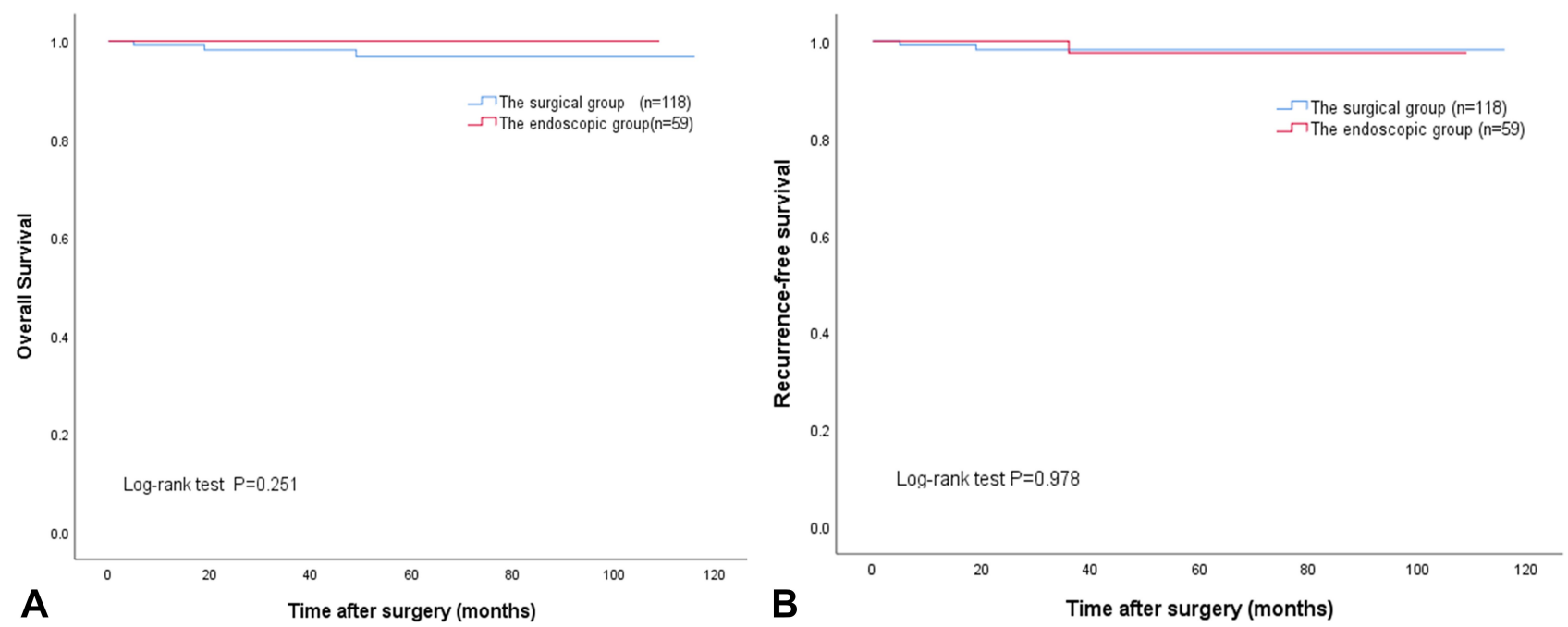

Figure 4 The difference between two groups of patients in overall survival $(\mathbf{A})$ or recurrence-free survival $(\mathbf{B})$ did not attain statistical significance $(P=0.25 \mathrm{I}$ and $\mathrm{P}=0.978$, respectively). 


\section{Discussion}

GISTs are among the most common mesenchymal tumors of the gastrointestinal tract. The tumor initiates in very early forms of special cells in the wall of the gastrointestinal tract, known as interstitial cells of Cajal, which are always referred to as the "pacemakers" of the gastrointestinal tract. ${ }^{12}$ Most cases of GISTs have activated mutations in C-KIT and $P D G F R A$. In recent years, studies have found that some drugs can target gene changes in GISTs' cells. For example, the target drugs Imatinib, Sunitinib, Regorafenib and Ripretinib have been successfully used to treat GISTs. ${ }^{13,14}$ Additionally, some new drugs, like Avapritinib (BLU-285), also have a very bright application prospect in the treatment of GISTs. $^{15}$

The development of laparoscopy has led to its gradual application in the treatment of GISTs. The laparoscopic resection of GISTs has been demonstrated to be feasible and safe. ${ }^{16-18}$ In the Chinese consensus guideline, ${ }^{5}$ laparoscopic surgery is recommended for tumors located at the greater curvature of the stomach or with diameter $\leq 5 \mathrm{~cm}$ of the anterior wall of the gastric fundus. Our data showed that it resulted in a shorter hospital stay (6.09 \pm 0.465 vs $7.79 \pm 0.273$ days; $\mathrm{p}=0.002$ ) and a higher hospital cost $(48,367.50 \pm 3,114.463$ vs $41,742.39 \pm 1,873.617$ RMB; $\mathrm{p}=0.041$ ), compared to the open surgery. Laparoscopy is a minimally invasive surgical technique, with some advantages over open surgical techniques in the treatment of 2$5-\mathrm{cm}$ gastric GISTs in terms of faster recovery after operation.

Due to the development of endoscopic resection and the biological behavior of GISTs (no lymph node metastasis), currently gastric GISTs can be resected using the endoscopy. Indeed, numerous studies ${ }^{19-21}$ have shown that the endoscopic resection of gastric GISTs of $<2 \mathrm{~cm}$ in diameter is safe and feasible. Our data reveal that endoscopic resection has advantages in bowel function recovery and hospital cost, compared with the surgical resection. Patients are more willing to accept endoscopic treatment because it results in less trauma, quicker recovery time and better cosmetic results. Some studies ${ }^{22,23}$ have demonstrated that endoscopic resection is a feasible and safe for $2-5 \mathrm{~cm}$ gastric GISTs. However, our data show that the incidence rate of complications (25.42 vs $4.20 \% ; \mathrm{p}<0.001)$ and reoperation (22.03 vs $0.00 \%$; $\mathrm{p}<0.001)$ in the endoscopic group was relatively higher than these in the surgical group. In the surgical group, our data show that 2 patients suffered from postoperative pulmonary infection, and 2 patients suffered from postoperative pulmonary embolism. These complications may be due to advanced age, long-term bed rest, wound pain, etc. However, in recent years, with the application of enhanced recovery after surgery in surgeries, ${ }^{24}$ these complications have been greatly reduced. In addition, there was a case of delayed bleeding after laparoscopic surgery, but after conservative treatment, the patient was uneventfully discharged from the hospital. Meanwhile, in the endoscopic group, leakage occurred in 5 patients. Additionally, after the endoscopic resection, 2 patients suffered from fever, abdominal pain and peritonitis. Fortunately, after fasting, nutritional support, infection treatment and gastric acid suppression treatment, the 2 patients recovered. However, unfortunately, 3 patients suffered from severe peritoneal cavity infection which physicians were not able to control. Ultimately, surgical treatment had to be implemented. It is worth mentioning that one patient with leakage spent two days in the intensive care unit after the surgery. Bleeding is also a common complication during the endoscopic resection. In our study, 4 patients had massive bleeding during the endoscopic resection, and underwent emergency surgery immediately. Endoscopic hemostasis is a safe and effective method to achieve immediate hemostasis for mucosal bleeding during the operation. However, this approach is somewhat tricky for serosal or intraperitoneal bleeding. Besides, gastric GISTs of 6 patients were not completely dissected due to the large tumor size and resection difficulty. As a result, surgeons had to perform surgical operations to remove the tumor completely in order to achieve R0 resection. The incidence rate of complications and reoperation in the endoscopic group is relatively higher than it in the surgical group. Balde et $\mathrm{al}^{25}$ also reached the same conclusion. Dong et $\mathrm{al}^{26}$ also found that laparoscopic resection is better than endoscopic dissection for $2-5 \mathrm{~cm}$ gastric GIST due to the lower complication rate and shorter hospital stay. Our data reveal that endoscopic resection is often associated with higher complication rate and higher reoperation rate than surgical resection. Once complications of endoscopic resection occur, most of them need to be solved by surgeries. This might raise potential risks in the treatment of patients and the physician-patient relationship might be deteriorated.

Our results also showed that patients in the endoscopic group had smaller tumor $(2.74 \pm 0.92 \mathrm{~cm}$ vs $3.78 \pm 1.10 \mathrm{~cm}$; $\mathrm{p}<0.001)$ and lower risk classification $(\mathrm{p}<0.001)$ than these in the surgical group. It may have been expected that 
endoscopic resection should also have advantages in OS and RFS than surgical resection, but this was not the case. This may be due to the small sample size and short followup period. Long-term outcomes of GISTs still require confirmation in more prospective studies or multi-center studies. However, one study ${ }^{27}$ did find a high local recurrence rate $(5.8 \%)$ after endoscopic enucleation of 86 GISTs, even though complete endoscopic resection was achieved in all cases. Accordingly, it is possible that endoscopic resection is not appropriate for $2-5 \mathrm{~cm}$ gastric GISTs. First, if the tumor is large, the endoscopist cannot completely remove it from the esophagus. Another report ${ }^{28}$ showed that gastric GIST with a minimum cross-sectional diameter of $<3.5 \mathrm{~cm}$ can be successfully removed through the upper digestive tract. Large gastric GIST can only be removed after being piecemeal resected in the stomach using an endoscope. Thus, the effect of endoscopic resection on GIST oncology is not clear. A systematic meta-analysis ${ }^{29}$ showed that the endoscopic resection was related to more patients with positive margins. The Japanese guidelines ${ }^{30}$ recommend ensuring that margins are both macroscopically and histologically negative, because non-R0 resection may influence the risk of local and peritoneal recurrences. Moreover, it was difficult for the endoscopist to protect tumor integrity when a $2-5 \mathrm{~cm}$ gastric GIST was resected, as the endoscopic resection of gastric GIST limited the operating space and visual field. If tumor rupture occurs during endoscopic resection, it perhaps not only requires postoperative adjuvant treatments but also increases the risk of poor prognosis. $^{31}$ These risk factors may affect the statistically significant differences between the two groups, despite finding smaller tumor and lower risk classification in the endoscopic group.

\section{Conclusion}

In conclusion, we still have a conservative attitude towards gastric GISTs in endoscopic treatments of $2-5 \mathrm{~cm}$, and recommend surgical treatments, choice especially laparoscopic surgery. However, in the future, it is possible that the endoscopic resection will play an indispensable role in the treatments of 2-5 cm gastric GISTs. More prospective clinical random control trials are warranted to settle this argument.

\section{Abbreviations}

CT, computed tomography; CD34, CD34 protein; CD117, CD117 protein; DOG1, discovered on GIST-1; GISTs, gastrointestinal stromal tumors; NIH, National Institutes of Health; OS, overall survival; PDGFRA, platelet-derived growth factor receptor $\alpha$; RFS, recurrence-free survival.

\section{Ethics Statement}

The study was approved by the Ethics Committee of Xiangya Hospital of Central South University, and informed consent was obtained from the patients. A signed informed consent was obtained from each patient in this study. Written informed consent has been provided by the 65-year-old patient in Figure 3 to have the case details and any accompanying images published. The study is in line with the Helsinki Declaration and does not violate medical ethics. All the research data were kept confidential and not used for commercial purposes.

\section{Funding}

This study was supported by the Hunan Provincial Clinical Medical Technology 299 Innovation Guidance Project, China (2018SK52604).

\section{Disclosure}

The authors declare that they have no competing interests.

\section{References}

1. Joensuu H, Hohenberger P, Corless CL. Gastrointestinal stromal tumour. Lancet. 2013;382(9896):973-983. doi:10.1016/S01406736(13)60106-3

2. Mantese G. Gastrointestinal stromal tumor: epidemiology, diagnosis, and treatment. Curr Opin Gastroenterol. 2019;35(6):555-559. doi:10.1097/MOG.0000000000000584

3. Raut CP, Espat NJ, Maki RG, et al. Efficacy and tolerability of 5-year adjuvant imatinib treatment for patients with resected intermediate- or high-risk primary gastrointestinal stromal tumor: the PERSIST-5 clinical trial. JAMA Oncol. 2018;4(12):e184060. doi:10.1001/jamaoncol. 2018.4060

4. Casali PG, Abecassis N, Bauer S, et al. Gastrointestinal stromal tumours: ESMO-EURACAN clinical practice guidelines for diagnosis, treatment and follow-up. Ann Oncol. 2018;29:iv68-iv78. doi:10.1093/annonc/mdy095

5. Li J, Ye Y, Wang J, et al. Chinese consensus guidelines for diagnosis and management of gastrointestinal stromal tumor. Chin J Cancer Res. 2017;29(4):281-293. doi:10.21147/j.issn.1000-9604.2017.04.01

6. von Mehren M, Randall RL, Benjamin RS, et al. Soft tissue sarcoma, Version 2.2018, NCCN clinical practice guidelines in oncology. J Natl Compr Canc Netw. 2018;16(5):536-563. doi:10.6004/jnccn.2018.0025

7. Chen TH, Hsu CM, Chu YY, et al. Association of endoscopic ultrasonographic parameters and gastrointestinal stromal tumors (GISTs): can endoscopic ultrasonography be used to screen gastric GISTs for potential malignancy? Scand J Gastroenterol. 2016;51(3):374-377. doi:10.3109/00365521.2015.1095350

8. Marcella C, Shi RH, Sarwar S. Clinical overview of GIST and its latest management by endoscopic resection in upper GI: a literature review. Gastroenterol Res Pract. 2018;2018:6864256. doi:10.1155/2018/ 6864256 
9. Clavien PA, Barkun J, de Oliveira ML, et al. The Clavien-Dindo classification of surgical complications: five-year experience. Ann Surg. 2009;250(2):187-196. doi:10.1097/SLA.0b013e3181b13ca2

10. Etherington MS, DeMatteo RP. Tailored management of primary gastrointestinal stromal tumors. Cancer. 2019;125(13):2164-2171. doi:10.1002/cncr.32067

11. Kou YW, Zhang Y, Fu YP, Wang Z. KIT and platelet-derived growth factor receptor alpha wild-type gastrointestinal stromal tumor associated with neurofibromatosis type 1: two case reports. World J Clin Cases. 2019;7(24):4398-4406. doi:10.12998/wjcc.v7.i24.4398

12. von Mehren M, Joensuu H. Gastrointestinal stromal tumors. J Clin Oncol. 2018;36(2):136-143. doi:10.1200/JCO.2017.74.9705

13. Schroeder BA, Kohli K, O’Malley RB, et al. Durable tumor regression in highly refractory metastatic KIT/PDGFRA wild-type GIST following treatment with nivolumab. Oncoimmunology. 2020;9 (1):1710064. doi:10.1080/2162402X.2019.1710064

14. Nemunaitis J, Bauer S, Blay JY, et al. Intrigue: Phase III study of ripretinib versus sunitinib in advanced gastrointestinal stromal tumor after imatinib. Future Oncol. 2020;16(1):4251-4264. doi:10.2217/ fon-2019-0633

15. BLU-285, DCC-2618 show activity against GIST. Cancer Discov. 2017;7(2):121-122.

16. Inaba CS, Dosch A, Koh CY, et al. Laparoscopic versus open resection of gastrointestinal stromal tumors: survival outcomes from the NCDB. Surg Endosc. 2019;33(3):923-932. doi:10.1007/s00464-0186393-8

17. Piessen G, Lefevre JH, Cabau M, et al. Laparoscopic versus open surgery for gastric gastrointestinal stromal tumors: what is the impact on postoperative outcome and oncologic results? Ann Surg. 2015;262 (5):831-839; discussion 829-840. doi:10.1097/SLA.000000 0000001488

18. Nakamori M, Iwahashi M, Nakamura M, et al. Laparoscopic resection for gastrointestinal stromal tumors of the stomach. Am J Surg. 2008;196(3):425-429. doi:10.1016/j.amjsurg.2007.10.012

19. Feng F, Liu Z, Zhang X, et al. Comparison of endoscopic and open resection for small gastric gastrointestinal stromal tumor. Transl Oncol. 2015;8(6):504-508. doi:10.1016/j.tranon.2015.11.008

20. Meng Y, Li W, Han L, et al. Long-term outcomes of endoscopic submucosal dissection versus laparoscopic resection for gastric stromal tumors less than $2 \mathrm{~cm}$. J Gastroenterol Hepatol. 2017;32 (10):1693-1697. doi:10.1111/jgh.13768
21. Zhang Q, Gao LQ, Han ZL, Li XF, Wang LH, Liu SD. Effectiveness and safety of endoscopic resection for gastric GISTs: a systematic review. Minim Invasive Ther Allied Technol. 2018;27(3):127-137. doi:10.1080/13645706.2017.1347097

22. He Z, Sun C, Zheng Z, et al. Endoscopic submucosal dissection of large gastrointestinal stromal tumors in the esophagus and stomach. J Gastroenterol Hepatol. 2013;28(2):262-267. doi:10.1111/jgh.12056

23. Chen L, Zhang Q, Li FY, et al. Comparison of treatment outcomes between laparoscopic and endoscopic surgeries for relatively small gastric gastrointestinal stromal tumors. Surg Oncol. 2018;27 (4):737-742. doi:10.1016/j.suronc.2018.10.002

24. Triantafyllou T, Olson MT, Theodorou D, Schizas D, Singhal S. Enhanced recovery pathways vs standard care pathways in esophageal cancer surgery: systematic review and meta-analysis. Esophagus. 2020;17(2):100-112. doi:10.1007/s10388-020-00718-9

25. Balde AI, Chen T, Hu Y, et al. Safety analysis of laparoscopic endoscopic cooperative surgery versus endoscopic submucosal dissection for selected gastric gastrointestinal stromal tumors: a propensity score-matched study. Surg Endosc. 2017;31(2):843-851. doi:10.1007/ s00464-016-5042-3

26. Dong X, Chen W, Cui Z, et al. Laparoscopic resection is better than endoscopic dissection for gastric gastrointestinal stromal tumor between 2 and $5 \mathrm{~cm}$ in size: a case-matched study in a gastrointestinal center. Surg Endosc. 2019. doi:10.1007/s00464-019-07251-6

27. Wang Y, Li Y, Luo H, Yu H. [Efficacy analysis of endoscopic submucosal excavation for gastric gastrointestinal stromal tumors]. Zhonghua Wei Chang Wai Ke Za Zhi. 2014;17(4):352-355. Chinese.

28. Repici A, Hassan C, De Paula Pessoa D, et al. Efficacy and safety of endoscopic submucosal dissection for colorectal neoplasia: a systematic review. Endoscopy. 2012;44(2):137-150. doi:10.1055/s-0031-1291448

29. Wang C, Gao Z, Shen K, et al. Safety and efficiency of endoscopic resection versus laparoscopic resection in gastric gastrointestinal stromal tumours: a systematic review and meta-analysis. Eur J Surg Oncol. 2020;46(4Pt A):667-674. doi:10.1016/j.ejso.2019.10.030

30. Nishida T, Hirota S, Yanagisawa A, et al. Clinical practice guidelines for gastrointestinal stromal tumor (GIST) in Japan: english version. Int J Clin Oncol. 2008;13(5):416-430. doi:10.1007/s10147-008-0798-7

31. Nishida T, Holmebakk T, Raut CP, Rutkowski P. Defining tumor rupture in gastrointestinal stromal tumor. Ann Surg Oncol. 2019;26 (6):1669-1675. doi:10.1245/s10434-019-07297-9

\section{Publish your work in this journal}

Cancer Management and Research is an international, peer-reviewed open access journal focusing on cancer research and the optimal use of preventative and integrated treatment interventions to achieve improved outcomes, enhanced survival and quality of life for the cancer patient.
The manuscript management system is completely online and includes a very quick and fair peer-review system, which is all easy to use. Visit http://www.dovepress.com/testimonials.php to read real quotes from published authors. 